\title{
CHRONIC LOW BACK PAIN; \\ EFFECTS OF THE LUMBAR STABILIZATION EXERCISES ON PAIN, RANGE OF MOTION AND FUNCTIONAL DISABILITY IN THE MANAGEMENT
}

1. Physical Therapist APS Special Education School, Hamza Camp Rawalpindi.

2. Assistant Professor

Riphah College of Rehabilitation Sciences

Riphah International University.

3. Principal Helping Hand

Institute of Rehabilitation Sciences Mansehra.

4. Principal

Institute of Physical Medicine and Rehabilitation

Khyber Medical University.

Correspondence Address:

Sehrish Ali

Physical Therapist

APS Special Education School,

Hamza Camp Rawalpindi.

sehrishali23@gmail.com

Article received on:

04/10/2016

Accepted for publication:

05/02/2017

Received after proof reading:

06/04/2017

\section{Sehrish Ali ${ }^{1}$, Abdul Ghafoor Sajjad ${ }^{2}$, Keramat Ullah Keramat ${ }^{3}$, Haider Darian ${ }^{4}$}

ABSTRACT... Background: Worldwide prevalence of chronic low back pain is $19.6 \%$ in those aged between 20-59 years and more prevalent in women. Routine physiotherapy appears to be effective in reducing pain and improving functional outcome in chronic low back pain patients. Lumbar stabilization exercises are trending in the management of chronic low back pain though it is not known whether addition of these exercises produce better results as compared to routine physiotherapy alone. Objectives: The objective of this study was to determine the effect of the lumbar stabilization exercises on pain, ROM and functional disability in the management of chronic low back pain. A randomized control trial. Period: February 2016 to July 2016. Setting: Rehab \& Research Center, Pakistan Railway General Hospital. Methodology: 42 chronic low back pain patients (02 drop outs, one from each group). The participants were recruited through purposive sampling technique. Random allocation was done through coin toss method into two groups Lumbar Stabilization Exercise (LSE) group $(n=20)$ and Conventional Physiotherapy (CPT) group $(n=20)$. Tools used to collect data were NPRS, Modified ODI, Goniometer (Lumbar Flexion, Extension and Side bendings) and MMT (Trunk Flexors and Extensors). The data was analyzed $(n=40)$ at baseline and later after 2 weeks of intervention (8 sessions) on IBM SPSS20. Results: 28 females and 12 males participated in the study with mean age of $38.88 \pm 12.69$. After 02 weeks of intervention both treatment groups showed improvement in decreasing pain and improving functional status. LSE group had significant gains in NPRS $p=0.001$, Modified ODI $p=0.001$, ROM Extension $p=0.027$, ROM Right side bend $p=0.024$ and MMT Flexion $p=$ 0.031 as compared to CPT group. Conclusion: Lumbar stabilization exercises in addition to conventional physiotherapy are found more effective in chronic low back pain management as compared to conventional physiotherapy alone in terms of reducing pain and functional disability.

Key words: Chronic Low Back Pain, CLBP, Lumbar Multifidis, Lumbar Stabilization Exercises, Transversus Abdominis.

Article Citation: Ali S, Sajjad AG, Karamat K, Darian H. Chronic low back pain; effects of the lumbar stabilization exercises on pain, range of motion and functional disability in the management. Professional Med J 2017;24(4):526-533.

DOI: $10.17957 / \mathrm{TPMJ} / 17.3645$

\section{INTRODUCTION}

Previous researches have showed that low back pain is a universal experience; approximately every person experiences this pain once at some point in their life span. It is the most frequent reason behind job-related disability and a leading contributor to missed work days. In 2010 low back pain was labeled as one of the most common cause for health care visits among musculoskeletal disorders. It is amongst the most frequently occurring health condition across the world and it places a considerable financial burden on individual as well as on community. People of all ages, ethnicities, genders and demographic areas across the globe are affected with low back pain in general with higher majority of females especially those aged between $40-80$ years. ${ }^{1-3}$

When it comes to the prevalence of low back pain in general sufficient literature is available on the other hand very little information is present when it comes to chronic low back pain specifically this is because there are different schools of thoughts about the definition of chronic low back pain. According to some chronic low back is the back pain that lasts for more than 7-12 weeks, while others classify recurrently occurring back pain as chronic pain as it affects an individual for a long 
period, lastly for some chronic low back pain is pain that lasts longer than the expected period of healing. According to a survey conducted in USA, back pain is the most pervasive cause of activity limitation in youngsters with age less than 45 years, the second most recurrent cause for doctor's visit, the fifth-ranking reason behind admission to hospital, and the third most common cause of surgical measures. ${ }^{4}$ The global prevalence of chronic low back pain was calculated in a systemic review done in year 2015 according to age and gender. The result showed that the occurrence of chronic low back pain was $19.6 \%$ in those aged between $20-59$ years and comparatively more prevalent in females. ${ }^{5}$

Therapeutic exercises for low back pain (LBP) have advanced with the passage of time. At present, the main aim of the exercises is to the stabilize the lumbar spine and maintain it. ${ }^{6}$ Lumbar stabilization, core stabilization, or segmental stabilization is multi-component exercise program that aims at improving strength, flexibility, and endurance. These active forms of exercises are designed to strengthen muscles, to support the spine and help prevent low back pain. In general it can be prescribed in the management of back pain episode at any time or after a detailed evaluation of the patient's condition. The initial step in the training of these stabilization exercises is to find and teach the neutral position of spine; this can be done with the initial help of experienced physical therapist. The muscles of the back are exercised to teach the spine how to stay in this position. Several groups of muscles are targeted, predominantly the transversus abdominis (TrA), lumbar multifidi, lumbar paraspinal, abdominal, diaphragmatic, and pelvic musculature.

The first stabilization exercise program for the activation and strengthening of the transverses abdominis and multifidus muscles was presented by Richardson et al. The basic concept was concerning the stability of the lumbar spine; according to them stability is affected by the power and endurance of TrA and lumbar MF muscles, strengthening these stabilizing muscles results in decreasing pain and improving functional outcome. They emphasized on the co-activation of the transverses abdominis and multifidus muscles by isometric contractions followed by further training of these muscles level by level. ${ }^{6}$

For the activation of $\operatorname{TrA}$ and lumbar mulifidus muscles patients are instructed to lie supine in hook lying position while maintaining neutral spine. Patient is asked to press the belly button in while exhaling. As patient isometrically contract the abdominal muscle the Transversus abdominis and lumbar multifidus co-activates. A number of techniques are used for this counter activation of muscles. If patient has difficulty in the activation of transverses abdominis, pressure biofeedback unit can be used for learning as it gives visual feedback. A small inflatable cuff is placed under the lumbar spine with pressure gauge in patient's hand. The cuff is inflated to $40 \mathrm{mmHg}$ and patient is asked to draw belly button in while exhaling. When patient exhales there should be $10 \mathrm{mmHg}$ raise in the reading. Patients should be able to perform at least 10 isometric hold for 10 seconds each without fatiguing. Once patient becomes comfortable with this technique the exercises can be advanced for individual muscle training. ${ }^{7}$

A study was conducted in 2010 by Fabio Renovato and colleagues on Segmental stabilization and muscular strengthening in chronic low back pain. They suggested that both techniques were effective as they decreased pain and reduced disability. Segmental stabilization was rated superior to superficial strengthening for all variables as superficial strengthening did not improve TrA activation capacity. ${ }^{8}$ Another study in year 2004 on the effect of lumbar stabilization exercise training on functional ability and quality of life in patients with chronic low back pain suggested that a program of lumbar stabilization is found effective in improving quality of life and functional outcome in patients with CLBP. ${ }^{9}$

\section{MATERIAL \& METHODS}

A randomized control trial was conducted from February 2016 to July 2016 at Riphah Rehabilitation \& Research Center, Pakistan Railway General Hospital. The participants were recruited through non probability purposive sampling technique. Forty two patients diagnosed 
with low back pain were included in the study; their symptoms were present for more than 3 months with limited ROM and aged between 2060 years. Patients with prolapsed intervertebral disc, spinal fracture, inflammatory condition, mass occupying lesion and radicular symptoms below knee were excluded from the study. After selection of patients random allocation was done through coin toss method into two groups Lumbar Stabilization Exercise (LSE) group $(n=21)$ and Conventional Physiotherapy (CPT) group $(n=21)$. A semi structured questionnaire was asked from each patient. First section of the questionnaire consisted of demographic data including name of the patient, age, gender, present address, contact number, occupation and mode of referral. Patients were then asked about their present symptoms, onset of their pain (duration), aggravating factors, relieving factors, use of medications, any previous treatment taken. Lastly patient was asked to report any previous physiotherapy treatment for the management of their low back pain. All the patients were assessed at baseline with NPRS, MMT (Trunk Flexors and Extensor), ROM (Lumbar Flexion, Extension and Side bendings) and Modified ODI prior to first treatment session and later at the end of last treatment session. The treatment protocol included application of TENS, Hot Pack, CPA spinal mobilization, Stretching exercises and Lumbar Stabilization Exercises. Two drop outs were reported, one from each group. A total of 8 treatment sessions were given to both groups, 4 days per week for two weeks. The data was analyzed $(n=40)$ at baseline and later after 2 weeks of intervention (8 sessions) on IBM SPSS-20.

\section{DATA ANALYSIS PROCEDURE}

The data was entered and analyzed on IBM Statistical Packages for Social Sciences (SPSS version 20). Mean and standard deviation was computed for quantitative variable i.e. age. Frequency and percentage were computed for categorical variable like gender, occupation, mode of referral, onset of pain, aggravating and relieving factors, medications and previous physiotherapy treatment. Normality of data was checked for the distribution of data, test result showed that NPRS, Modified ODI, ROM's and MMT data was not normally distributed so the test of choice for comparison within the groups was Wilcoxon test and for comparison between CPT and LSE group was Mann Whitney U Test.

\section{RESULTS}

A total of 42 chronic low back pain patients (02 drop out) participated in the study. The participants were recruited through non probability purposive sampling technique. Random allocation was done through coin toss method into two groups Lumbar Stabilization Exercise (LSE) group $(n=20)$ and Conventional Physiotherapy (CPT) group $(n=20)$.

The mean age of all participants was $38.88 \pm 12.69$. The mean age for LSE group was $31.75 \pm 9.10$ whereas for CPT group it was $46 \pm 11.88$. 28. Out of 40 patients 28 were females and 12 males. 15 females, 5 males were found in LSE group while 13 females and 7 males in the CPT group. Overall majority (42\%) of the patients were housewives, among them $60 \%$ were found in the CPT group. In LSE group the most common occupation found was medical professionals and students' $30 \%$ each. In general, $37.5 \%$ participants were self-referred, $27.5 \%$ from orthopedic and same percentage $27.5 \%$ through OPD.

In CPT group $45 \%$ were referred from orthopedic whereas for LSE group the majority of patients $60 \%$ were self-referred. Most of the patient (62\%) reported onset of low back pain for more than a year. LSE group majority for onset of pain was $62 \%$ and that for CPT group was $60 \%$. The most common stated aggravating factor was pain progression with the day i.e. $35 \%$ next to it was prolong sitting and bending $27.5 \%$ each. For CPT group 35\% patients reported prolong sitting as symptom aggravating factor but for LSE group $45 \%$ individuals commonly complained aggravating factor was pain progression with the day progression. Majority of the participants (72\%) marked lying as relieving factor irrespective of the group division, $85 \%$ in LSE group and $60 \%$ in CPT group. Overall $87.5 \%$ of patients already took medicines for the relief of their symptoms, 
percentage was found high even within the group i.e. $85 \%$ for LSE group and $90 \%$ for CPT group. Overall 55\% patients took physiotherapy treatment before with their majority in CPT group i.e. 55\% but for LSE Group the 65\% patients reported they never received any physiotherapy before. When asked in general about the previous treatment $47.5 \%$ participants stated treatment from orthopedic with their majority $(60 \%)$ in CPT group whereas in LSE group the percentage of self-medication was reported higher i.e. 55\%.9 (Table-I)

Within the group comparison for the Conventional Physiotherapy (CPT) group Wilcoxon test results showed significant results for the following variables, the $p$ value for NPRS was $<.001$ which was significant. The $p$ value for Modified ODI was $<.001$ which was significant. The $p$ value for ROM Flexion was <.001 which was significant. The $\mathrm{p}$ value for ROM Extension was $<.001$ which was significant. The $p$ value for ROM Right Side Bending was .003 which was significant. The $p$ value for ROM Left Side Bending was .005 which was significant. The results were not significant for MMT Trunk Flexors with $p$ value of 1.000 . The $p$ value for MMT Trunk Extensors was 1.000 (Table-II)

Within the group comparison in the Lumbar Stabilization Exercise (LSE) group Wilcoxon test results showed the $p$ value for NPRS was $<.001$ which was significant. The $p$ value for Modified ODI was $<.001$ which was significant. The $p$ value for ROM Flexion was <.001 which was significant. The $p$ value for ROM Extension was <.001 which was significant. The $p$ value for ROM Right Side Bending was .002 which was significant. The $p$ value for ROM Left Side Bending was .003 which was significant. The results were not significant for MMT Trunk Flexors with $p$ value of 1.000 . The $p$ value for MMT Trunk Extensors was .317. (Table-III)

Between the group comparison Mann Whitney $U$ test was applied at baseline and then after 2 weeks (8 sessions) of intervention. The base line values comparison between Conventional Physiotherapy (CPT) group and Lumbar Stabilization Exercises (LSE) group showed no significant results for the following. The $p$ value for NPRS was .547 which was not significant. The $p$ value for Modified ODI was .302 which was not significant. The $p$ value for ROM Flexion was .578 which was not significant. The $p$ value for ROM Right side bending was .064 which was not significant. The $p$ value for ROM Left Side Bending was .141 which was not significant. The $p$ value for MMT Trunk Flexor was .059 which was not significant. The $p$ value for MMT Trunk Extensor was .959 which was not significant. (Table-IV)

\begin{tabular}{|c|c|c|c|}
\hline Variables & Overall & LSE Group & CPT Group \\
\hline Age & Mean Age38.88 \pm 12.69 & Mean Age $31.75 \pm 9.10$ & Mean Age $46 \pm 11.88$ \\
\hline Gender & $\begin{array}{l}28 \text { Female } \\
12 \text { Male }\end{array}$ & $\begin{array}{l}15 \text { Female } \\
5 \text { Male }\end{array}$ & $\begin{array}{l}13 \text { Female } \\
7 \text { Male }\end{array}$ \\
\hline Occupation & $\begin{array}{l}42 \% \text { Housewives } \\
17.5 \% \text { Medical Professional } \\
17.5 \% \text { Student }\end{array}$ & $\begin{array}{l}30 \% \text { Medical Professional } \\
30 \% \text { Student }\end{array}$ & $60 \%$ Housewives \\
\hline Referral & $\begin{array}{l}37 \% \text { Self-Referral } \\
27.5 \% \text { Orthopedic } \\
27.5 \% \text { OPD }\end{array}$ & $60 \%$ Self & $45 \%$ from Orthopedic \\
\hline Onset of Pain & $\begin{array}{l}62 \% \text { More than a year } \\
15 \% 6 \text { Months before } \\
12.5 \% 3 \text { months before }\end{array}$ & $65 \%$ for More than a Year & $60 \%$ for More than a year \\
\hline Aggravating Factors & $\begin{array}{l}35 \% \text { as day progresses } \\
27.5 \% \text { Sitting } \\
27.5 \% \text { Bending }\end{array}$ & $45 \%$ as day progresses & $35 \%$ while sitting for long \\
\hline Relieving Factors & $72 \%$ Lying & $85 \%$ lying & $60 \%$ while lying \\
\hline Medications & $\begin{array}{l}87.5 \% \text { Yes } \\
12.5 \% \text { No }\end{array}$ & $85 \%$ Yes & $90 \%$ yes \\
\hline $\begin{array}{l}\text { Previous PT } \\
\text { Treatment }\end{array}$ & $\begin{array}{l}55 \% \text { No } \\
45 \% \text { Yes }\end{array}$ & $65 \%$ No & $55 \%$ yes \\
\hline
\end{tabular}

Table-I. Demographic Data 


\begin{tabular}{|c|c|c|c|c|c|c|c|}
\hline Test Variable & \multicolumn{2}{|c|}{ Pre Median \pm IQ } & \multicolumn{2}{|c|}{ Post Median $\pm I Q$} & Mean Rank & $Z$ Value & P Value \\
\hline NPRS & \multicolumn{2}{|c|}{$6(1)$} & \multicolumn{2}{|c|}{$1(1.5)$} & 10.50 & -4.018 & $<.001$ \\
\hline Modified ODI & \multicolumn{2}{|l|}{$48(16)$} & \multicolumn{2}{|l|}{$19(12.5)$} & 10.50 & -3.927 & $<.001$ \\
\hline ROM Flexion & \multicolumn{2}{|l|}{$47(9.5)$} & \multicolumn{2}{|l|}{$50(8.25)$} & 8.50 & -3.556 & $<.001$ \\
\hline ROM Extension & \multicolumn{2}{|l|}{$12.5(5)$} & \multicolumn{2}{|l|}{$15(5.75)$} & 9.00 & -3.689 & $<.001$ \\
\hline ROM Rt. Side Bending & \multicolumn{2}{|l|}{$13.5(2.75)$} & \multicolumn{2}{|l|}{$15(3)$} & 6.00 & -2.969 & .003 \\
\hline ROM Lt. Side Bending & $14.5(4.5)$ & & $15(2.5)$ & & 5.50 & -2.829 & .005 \\
\hline MMT Trunk Flexors & $3(0)$ & & $3(0)$ & & 0.00 & 0.000 & 1.000 \\
\hline MMT Trunk Extensors & $3(0)$ & & $3(0)$ & & 0.00 & 0.000 & 1.000 \\
\hline & Table- & I Pre \& F & ost compari & n withi & in the CPT Grou & & \\
\hline Test Variable & Pre Medi & an $\pm I Q$ & Post Mec & $n \pm I Q$ & Mean Rank & Z Value & P Value \\
\hline NPRS & $6(2.75)$ & & $0(0)$ & & 10.50 & -4.025 & $<.001$ \\
\hline Modified ODI & $46(20)$ & & $12(9.5)$ & & 10.50 & -3.924 & $<.001$ \\
\hline ROM Flexion & $49.5(11.75)$ & & $53(7)$ & & 9.00 & -3.639 & $<.001$ \\
\hline ROM Extension & $16.5(8)$ & & $20(7.75)$ & & 9.00 & -3.684 & $<.001$ \\
\hline ROM Rt. Side Bending & $16(7)$ & & $16.5(5.5)$ & & 6.50 & -3.165 & .002 \\
\hline ROM Lt. Side Bending & $16(5.5)$ & & $16.5(5)$ & & 6.00 & -2.969 & .003 \\
\hline MMT Trunk Flexors & $3(1)$ & & $3(0)$ & & 1.50 & 0.000 & 1.000 \\
\hline MMT Trunk Extensors & $3(0)$ & & $3(0)$ & & 1.00 & -1.000 & .317 \\
\hline & Table-I & I. Pre \& & Post compar & on withi & in the LSE Gro & & \\
\hline Variable & Group & Med & $\operatorname{an} \pm \mathrm{IQ}$ & Mean & Rank & Z Value & P Value \\
\hline NPRS & $\begin{array}{l}\text { CPT Group } \\
\text { LSE Group }\end{array}$ & $\begin{array}{l}6(1) \\
6(1.75\end{array}$ & & $\begin{array}{l}19 . \\
21 .\end{array}$ & $\begin{array}{l}.50 \\
.50\end{array}$ & -0.563 & .573 \\
\hline Modified ODI & $\begin{array}{l}\text { CPT Group } \\
\text { LSE Group }\end{array}$ & $\begin{array}{l}48(15 . \\
46(20)\end{array}$ & & & .40 & -1.032 & .302 \\
\hline ROM Flexion & $\begin{array}{l}\text { CPT Group } \\
\text { LSE Group }\end{array}$ & $\begin{array}{l}47(9.5 \\
49.5(1\end{array}$ & ) & & $\begin{array}{l}.48 \\
.53\end{array}$ & -0.557 & .578 \\
\hline ROM Extension & $\begin{array}{l}\text { CPT Group } \\
\text { LSE Group }\end{array}$ & $\begin{array}{l}12.5(5 \\
16.5(8\end{array}$ & & & $\begin{array}{l}.63 \\
.38\end{array}$ & -2.115 & .034 \\
\hline $\begin{array}{l}\text { ROM Rt. Side } \\
\text { Bending }\end{array}$ & $\begin{array}{l}\text { CPT Group } \\
\text { LSE Group }\end{array}$ & $\begin{array}{l}13.5(4 \\
16(7)\end{array}$ & 75) & $\begin{array}{l}17 . \\
23 .\end{array}$ & $\begin{array}{l}.10 \\
.90\end{array}$ & -1.856 & .064 \\
\hline $\begin{array}{l}\text { ROM Lt. Side } \\
\text { Bending }\end{array}$ & $\begin{array}{l}\text { CPT Group } \\
\text { LSE Group }\end{array}$ & $\begin{array}{l}14.5(4 \\
16(5.5\end{array}$ & & & .80 & -1.473 & .141 \\
\hline $\begin{array}{l}\text { MMT Trunk } \\
\text { Flexors }\end{array}$ & $\begin{array}{l}\text { CPT Group } \\
\text { LSE Group }\end{array}$ & $\begin{array}{l}3(0) \\
3(1)\end{array}$ & & $\begin{array}{l}17 . \\
23 .\end{array}$ & .95 & -1.901 & .057 \\
\hline $\begin{array}{l}\text { MMT Trunk } \\
\text { Extensors }\end{array}$ & $\begin{array}{l}\text { CPT Group } \\
\text { LSE Group }\end{array}$ & $\begin{array}{l}3(0) \\
3(0)\end{array}$ & & & $\begin{array}{l}.45 \\
.55\end{array}$ & -0.052 & .959 \\
\hline
\end{tabular}

Table-IV. Comparison between CPT and LSE Group at baseline

Mann Whitney U Test was applied after 2 weeks (8 sessions) of intervention. The post interventional values comparison between Conventional Physiotherapy (CPT) group and Lumbar Stabilization Exercises (LSE) group showed significant results for the following.

The NPRS median \pm IQ value in CPT group was 1 (1.50) and for LSE group was 0 (0) with a mean rank of 26.15 for CPT group whereas it was 14.85 for LSE group. $Z$ value was -3.377 and $p$ value of .001 which was significant. The Modified ODI median \pm IQ value in CPT group was 19 (12.5) and for LSE group was 12 (9.5) with a mean rank of 26.23 for CPT group whereas it was 14.78 for
LSE group. Z value was -3.109 and $p$ value of .001 which was significant. The ROM Extension median \pm IQ value in CPT group was 15 (5.75) and for LSE group was 20 (7.75) with a mean rank of 16.45 for CPT group whereas it was 24.55 for LSE group. $Z$ value was -2.215 and $p$ value of .027 which was significant. The ROM Right side bending median $\pm I Q$ value in CPT group was 15 (3) and for LSE group was 16.5 (5.75) with a mean rank of 16.40 for CPT group whereas it was 24.60 for LSE group. $Z$ value was -2.256 and $p$ value of .024 which was significant.

The MMT for Trunk Flexor median $\pm I Q$ value in CPT group was 3 (0) and for LSE group was 3 (1) 
with a mean rank of 17.50 for CPT group whereas it was 23.50 for LSE group. Z value was -2.163 and $p$ value of .031 which was significant. The MMT for Trunk Extensor median \pm IQ value in CPT group was $3(0)$ and for LSE group was $3(0)$ with a mean rank of 21.00 for CPT group whereas it was 20.00 for LSE group. $Z$ value was -0.593 and $p$ value of .053 which was significant. The ROM Flexion median \pm IQ value in CPT group was 50
(8.25) and for LSE group was 53 (7) with a mean rank of 17.83 for CPT group whereas it was 23.18 for LSE group. $Z$ value was -1.459 and $p$ value of .145 which was not significant. The ROM Left side bending median \pm IQ value in CPT group was 15 (2.5) and for LSE group was 16.5 (5) with a mean rank of 17.50 for CPT group whereas it was 23.50 for LSE group. $Z$ value was -1.661 and $p$ value of .097 which was not significant. (Table-V)

\begin{tabular}{|c|c|c|c|c|c|}
\hline Variable & Group & Median $\pm I Q$ & Mean Rank & Z Value & P Value \\
\hline NPRS & $\begin{array}{l}\text { CPT Group } \\
\text { LSE Group }\end{array}$ & $\begin{array}{l}1(1.5) \\
0(0)\end{array}$ & $\begin{array}{l}26.15 \\
14.85\end{array}$ & -3.377 & .001 \\
\hline Modified ODI & $\begin{array}{l}\text { CPT Group } \\
\text { LSE Group }\end{array}$ & $\begin{array}{l}19(12.5) \\
12(9.5)\end{array}$ & $\begin{array}{l}26.23 \\
14.78\end{array}$ & -3.109 & .001 \\
\hline ROM Flexion & $\begin{array}{l}\text { CPT Group } \\
\text { LSE Group }\end{array}$ & $\begin{array}{l}50(8.25) \\
53(7)\end{array}$ & $\begin{array}{l}17.83 \\
23.18\end{array}$ & -1.459 & .145 \\
\hline ROM Extension & $\begin{array}{l}\text { CPT Group } \\
\text { LSE Group }\end{array}$ & $\begin{array}{l}15(5.75) \\
20(7.75)\end{array}$ & $\begin{array}{l}16.45 \\
24.55\end{array}$ & -2.215 & .027 \\
\hline $\begin{array}{l}\text { ROM Rt. Side } \\
\text { Bending }\end{array}$ & $\begin{array}{l}\text { CPT Group } \\
\text { LSE Group }\end{array}$ & $\begin{array}{l}15(3) \\
16.5(5.75)\end{array}$ & $\begin{array}{l}16.40 \\
24.60\end{array}$ & -2.256 & .024 \\
\hline $\begin{array}{l}\text { ROM Lt. Side } \\
\text { Bending }\end{array}$ & $\begin{array}{l}\text { CPT Group } \\
\text { LSE Group }\end{array}$ & $\begin{array}{l}15(2.5) \\
16.5(5)\end{array}$ & $\begin{array}{l}17.50 \\
23.50\end{array}$ & -1.661 & .097 \\
\hline $\begin{array}{l}\text { MMT Trunk } \\
\text { Flexors }\end{array}$ & $\begin{array}{l}\text { CPT Group } \\
\text { LSE Group }\end{array}$ & $\begin{array}{l}3(0) \\
3(1)\end{array}$ & $\begin{array}{l}17.50 \\
23.50\end{array}$ & -2.163 & .031 \\
\hline
\end{tabular}

Table-V. Comparison between CPT and LSE Group after 2 weeks Intervention

\section{DISCUSSION}

This study suggests that lumbar stabilization exercises along with conventional physiotherapy are more effective in the management of chronic low back pain as compared to conventional physiotherapy alone in terms of reducing pain and improving functional status. Literature also supports that lumbar stabilization exercises lessen pain and improves functional status of patients with chronic low back pain.

In this study NPRS was used as a tool for measuring pain, the results showed improvement for both groups (CPT and LSE) but LSE group showed more significant results for pain reduction. For functional status outcome modified ODI was used. Functional status of both groups (CPT and LSE) improved but results were more significant for the LSE group. A randomized clinical study done by Anita Stankovic and colleagues (2012) on the lumbar stabilization exercises in addition to strengthening and stretching exercises reduce pain and improves function in chronic low back pain patients indicated that stabilization exercise along with traditional exercises is effective in decreasing pain and improves functional outcome in patients with chronic low back pain. This study was conducted from January 2007 to March 2009. 160 patients with chronic low back pain participated in the study and were divided into two equal groups. The study group performed lumbar stabilization exercises while the control group performed stretching and strengthening exercises. After intervention pain was successfully reduced in both groups with higher statistical significance in the study group. Improvement in ODI score was statistically more significant in the study group compared to the control group. Their study concluded that in chronic low back pain, stabilization exercises in addition to traditional programs are more effective in pain reduction and functional improvement in patients. ${ }^{10}$

A randomized control trail by Goldby at al (2006) was done on the efficacy of musculoskeletal physiotherapy for the management of chronic low back disorder. 346 patients participated in the study and were divided in to two groups; manual therapy group and stabilization exercises group. Data was collected at baseline, 3, 6, 12, and 24 
months for pain intensity, functional disability, medication, and quality of life. The results indicated statistically significant improvements in support of the spinal stabilization group. They concluded that the spinal stabilization program is more effective in the management of chronic low back pain in contrary to manual therapy or education booklet over time. ${ }^{11}$

Another RCT conducted in UK by Cairns and colleagues (2006) compared lumbar stabilization exercises to conventional physical therapy in patients with recurrent low back pain. 97 patients were recruited into either interventional or control group aging between 18-60 years. For functional outcome Roland Morris disability questionnaire was used. No statistically significant difference between the control and interventional group was reported for any of the outcomes measures. Hence they concluded that both treatment protocols showed improvement to a similar degree. There was no additional benefit of adding specific spinal stabilization exercises to a conventional physiotherapy for patients with recurrent low back pain. ${ }^{12}$

A comparative study by Fábio Renovato França and colleagues (2010) was done to find the effectiveness of two exercise programs, segmental stabilization exercises and strengthening of trunk muscles, on pain, functional disability, and activation of the transversus abdominis muscle $(\operatorname{TrA})$, in individuals with chronic low back pain. 30 individuals participated in their study; they were randomly assigned to any of two treatment groups. In the segmental stabilization exercise group $\operatorname{TrA}$ and lumbar multifidus muscles were focused, in the superficial strengthening group rectus abdominis, Internal oblique, external oblique and erector spinae were focused. Tools used included visual analogical scale and McGill pain questionnaire for pain, Oswestry disability questionnaire, and $\operatorname{TrA}$ muscle activation capacity through Pressure Biofeedback Unit. The treatment was given for 6 weeks, twice a week (12 sessions of 30-minute each). Results showed as compared to baseline, both treatments were useful in reducing pain and improving disability. Individuals in the segmental stabilization group had considerable gains for all variables when compared to control group. So they concluded that both techniques lessened pain and reduced disability. Therefore they concluded Segmental stabilization is superior to superficial strengthening for all variables. Superficial strengthening does not improve TrA activation capacity. ${ }^{8}$

The current study results were analyzed after 8 treatment sessions given over 2 weeks. A metaanalysis was conducted to review core stability exercises against general exercises for managing chronic low back pain. They included articles published from 1970 to October 2011. In the analysis a total of 5 RCTs were included involving 414 participants. The results revealed that shortterm follow-up core stability exercises were better than general exercises in pain reduction and disability, whereas no significant differences were found between core stability exercises and general exercises in reducing pain in long terms i.e. 6 months. They concluded that in chronic low back pain patients general exercises as compared to core stability exercises are more effective in terms of pain reduction and functional status in the short term. However, no significant long-term differences in pain severity were reported between patients who were involved in core stability exercises versus those in general exercises. ${ }^{13}$

In the current study we included the patients of chronic low back pain (pain for more than 3 months) aged between 20 - 60 years. Among the 40 sample size the mean age of the patients was $38.88 \pm 12.69$ having 28 females' 12 males. Literature is full with information about the prevalence of back pain in general, but when it comes to chronic low back pain, less information is available. This is because of different school of thoughts. Some label chronic back pain that lasts for more than 7-12 weeks. Others define it as pain that lasts further than the expected period of healing. Many classify recurrently occurring back pain as chronic pain as it affects an individual for a long period. A systemic review was done by Rodrigo Dalke at el (2015) to estimate worldwide prevalence of chronic low back pain according to age and gender. It suggested that the prevalence of chronic low back pain was $19.6 \%$ 
in those aged between 20-59 years and found more prevalent in women. (5) A review on the epidemiological features of chronic low back pain by Gunnar B J Andersson (1999) suggested that back impairments were more prevalent in women (70.3 per 1000 population) as compared to men (57.3 per 1000 population). Most commonly occurring among 18 to 64 (18-44 years 80.5 per 1000 population, 45-64 years $90 \cdot 1$ per 1000 population). ${ }^{4}$

\section{CONCLUSION}

The study results conclude that both treatment groups showed improvement by reducing pain and improving functional status outcome but lumbar stabilization exercises were found more effective in the management of chronic low back pain as compared to conventional physiotherapy alone. The mean age of LSE group was comparatively lesser as compared to control group as we used lottery method for the randomization of patients. This is one of the limitations of our study, future studies can be conducted with specific age group and larger sample size.

\section{COPYRIGHT@ 05 FEB, 2017.}

\section{REFERENCES}

1. Charles G. (Chad) Helmick M. The Burden of Musculoskeletal Diseases in the United States (BMUS). United States of America 2014 [cited 201624 July]; 4th:[Available from: http://www. boneandjointburden.org.

2. Gunnar Andersson M, PhD. United States Bone and Joint Initiative: The Burden of Musculoskeletal Diseases in the United States (BMUS). 2014 [cited 20165 August]; Third Edition:[Available from: http://www.boneandjointburden. org/2014-report/iid0/burden-back-pain.

3. Hoy D, Bain C, Williams G, March L, Brooks P, Blyth F, et al. A systematic review of the global prevalence of low back pain. Arthritis \& Rheumatism. 2012;64(6):2028-37.
4. Andersson GB. Epidemiological features of chronic low-back pain. The lancet. 1999;354(9178):581-5.

5. Meucci RD, Fassa AG, Faria NMX. Prevalence of chronic low back pain: systematic review. Revista de saude publica. $2015 ; 49$.

6. Richardson C, Jull G, Hodges P, Hides J. Therapeutic Exercise for Spinal Segmental Stabilization in Low Back Pain: Scientific Basis and Clinical Approach. 1999.

7. Standaert CJ, Weinstein SM, Rumpeltes J. Evidenceinformed management of chronic low back pain with lumbar stabilization exercises. The spine journal. 2008;8(1):114-20.

8. França FR, Burke TN, Hanada ES, Marques AP. Segmental stabilization and muscular strengthening in chronic low back pain: a comparative study. Clinics. 2010;65(10):1013-7.

9. Shaughnessy M, Caulfield B. A pilot study to investigate the effect of lumbar stabilisation exercise training on functional ability and quality of life in patients with chronic low back pain. International journal of rehabilitation research. 2004;27(4):297-301.

10. Stankovic A, Lazovic M, Kocic M, Dimitrijevic L, Stankovic I, Zlatanovic D, et al. Lumbar stabilization exercises in addition to strengthening and stretching exercises reduce pain and increase function in patients with chronic low back pain: randomized clinical openlabel study. life. 2012;2:3.

11. Goldby LJ, Moore AP, Doust J, Trew ME. A randomized controlled trial investigating the efficiency of musculoskeletal physiotherapy on chronic low back disorder. Spine. 2006;31(10):1083-93.

12. Cairns MC, Foster NE, Wright C. Randomized controlled trial of specific spinal stabilization exercises and conventional physiotherapy for recurrent low back pain. Spine. 2006;31(19):E670-E81.

13. Wang X-Q, Zheng J-J, Yu Z-W, Bi X, Lou S-J, Liu J, et al. A meta-analysis of core stability exercise versus general exercise for chronic low back pain. PloS one. 2012;7(12):e52082.

\section{AUTHORSHIP AND CONTRIBUTION DECLARATION}

\begin{tabular}{|c|c|c|c|}
\hline Sr. \# & Author-s Full Name & Contribution to the paper & Author $=\mathbf{s}$ Signature \\
\hline 1 & Sehrish Ali & Data collection thesis writing & \\
\hline 2 & Abdul Ghafoor Sajjad & Analysis the result & \\
\hline 3 & Keramat Ullah Keramat & Review the discussion & \\
\hline 4 & Haider Darian & Review the methodology & \\
\hline
\end{tabular}

